AARP INTERNATIONAL THE JOURNAL

VOLUME $11-2018$ EDITION

AARP

Real Possibilities

\title{
Liquidity and Sidecar Savings
}

By Will Sandbrook 


\title{
Liquidity and Sidecar Savings
}

\author{
By Will Sandbrook
}

$\mathrm{P}$ eople tend to manage their money in distinct "jars" for distinct goals, either literally or metaphorically. It could be a savings jar for a deposit on a house, a jar for monthly bills, or a jar for funding travels we plan to undertake when we finally retire and have enough free time. Whatever our goals, and however separate they may seem, they are in fact highly connected. And the breakdown of one can negatively affect the others. In the United Kingdom many peoples' pension jars are starting to build, and saving for retirement is rapidly becoming the norm. Thanks to mandatory auto enrollment, over 8 million people are now newly saving or saving more for later life, and opt-out rates remain low across the country. This is a great example of (now Noble Prize winner) Richard Thaler and Cass Sunstein's nudge theory working in practice.

In contrast, initiatives to encourage greater levels of liquid savings have not had quite the same impact. Incentives such as increasing the tax-free savings allowance and offering a credit match on savings have helped. But the reality is that many peoples' emergency savings jars are running low, or are completely empty. Money Advice Service research highlights the extent of this situation, revealing that only 42 percent of the UK working population has $£ 500$ (around USD 672) or more in liquid savings and 26 percent have nothing.

For those with little or no money put aside for today, the occurrence of a high or unexpected cost can have a severe impact. A car or a household appliance may break down and need replacing everyday situations we've all faced. But, without cash savings, many will have no choice but to use alternative methods to cover the expense. Options may include turning to friends and family, using ex- isting credit cards, or reducing spending wherever possible. But many might have to cancel pension contributions to free up cash or resort to high-cost sources of borrowing that, if not managed carefully, could lead to debt spirals. And in these circumstances, it's not just the debt itself that's the issue. Prolonged financial pressure can cause excessive levels of stress, which can have a knockon effect on people's health, productivity, and earning capacity.

So what can be done? Products and tools for savers may need to evolve to better reflect both the psychology of mental accounting and the need for flexibility between "jars."

With many people now building up meaningful retirement savings, it's been suggested previously that the defined-contribution (DC) pension system should be opened up to some level of early access. The rationale is that if individuals have access to enough liquid savings they're more likely to avoid damaging financial shocks that can have a long-lasting effect on their financial resilience, including into retirement.

However, although it is intuitively attractive, allowing this type of access creates a number of issues. Evidence from the US $401(\mathrm{k})$ system confirms that people look to their retirement savings to cope in emergencies, but also that this can create a significant degree of permanent "leakage." Some estimates suggest that as much as 40 cents of every $\$ 1$ saved is withdrawn before retirement.

A further concern is that DC pensions simply aren't designed for bank account-style access. They're intended for long-term saving and, for most of a working life, should have a relatively high-risk exposure. This makes DC accounts a poor fit to fund emer- gencies, which may well occur at the "wrong" moment in terms of fund value. In addition, the administration involved to withdraw this money could create a significant cost because the systems aren't designed for this purpose. All in all, these factors could lead to diminished outcomes for the saver.

However, an innovative new approach may offer a solution. Professor Brigitte Madrian, working with colleagues at Harvard and Yale, and, more recently, David John from AARP and Mark Iwry of the Brookings Institution have proposed an early access model that separates payroll contributions into a liquid sidecar account, run like a traditional savings account, and the main retirement account. When the balance in the liquid account exceeds a savings cap, all future contributions roll into the retirement account until the liquid account balance is needed, at which point contributions would top it back up to the savings cap. This appears to the saver much like a single product or savings tool, but with distinct underlying jars designed for their specific purposes and time horizons.

This builds on the idea presented by the team at Harvard that there's a potentially optimal balance between liquid and illiquid savings. In a UK context, the approach would build on the success of auto enrollment by adding a liquid savings component, and creating greater integration between these two savings jars. Importantly, it would do so by creating an additional flow of contributions over and above retirement contributions. This increases the overall amount saved, not only minimizing leakage from retirement savings but potentially creating a pre-commitment mechanism for savers to increase future retirement contributions if they first build up sufficient liquid savings. 


\section{"Thanks to mandatory auto enrollment, over}

8 million people are now newly saving or saving more for later life, and opt-out rates remain low across the country. This is a great example of (now Noble Prize winner) Richard Thaler and Cass Sunstein's nudge theory working in practice."

The sidecar idea fits into the broader category of hybrid financial products, advanced by the Aspen Institute among others. Unlike traditional products that offer one financial function, hybrid products combine two or more, enabling their design to fit more closely with the way people actually manage their money.

Our team at the National Employment Savings Trust (NEST) Insight unit is excited, both by this specific sidecar idea and by the broader concept of what hybrid products can do to enhance financial resilience and retirement outcomes for our target group of low- to moderate-income savers. But a number of questions remain about how it might work in practice. What does an appropriate and affordable contribution level look like, and what should the savings cap be? Would savers limit themselves to emergency use of the sidecar account or would it become another current account? And would the approach result in greater financial well-being, increased retirement savings, and reduced reliance on high-cost debt?

To answer these questions we're working in partnership with Professor Madrian and her team, along with the United Kingdom's Money Advice Service, to develop and conduct a research trial. We're currently planning the research and hope to start the two-year trial in 2018.

Excitingly, this appears to be an idea with genuinely international reach.
As part of our work we're collaborating with organizations planning similar trials in the United States and New Zealand, including AARP among others, to share our ideas about how to structure the sidecar and how to evaluate its impact. We hope the range of programs looking at variations of the sidecar idea will mean that a much stronger body of evidence from its practical application can emerge quickly to bolster the theoretical promise that it holds.

As with all our research, we'll make our findings widely and freely available to maximize their reach and the potential benefit to savers. And as new research emerges, we look forward to working closely with our counterparts and peers around the globe to tackle the liquid savings challenge and help people create an optimal balance of money in their savings jars.

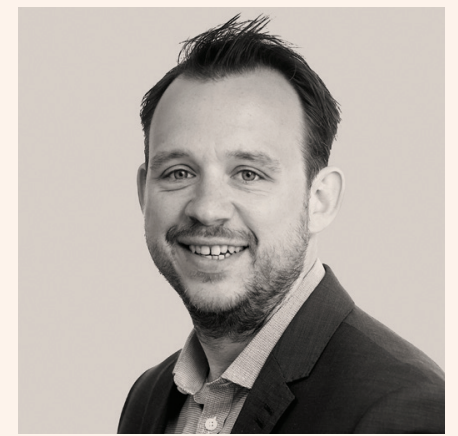

Will Sandbrook EXECUTIVE DIRECTOR NEST INSIGHT UNITED KINGDOM 
AARP International engages global stakeholders to spark solutions that strengthen communities, protect the vulnerable and enable people around the world to pursue their goals and dreams. Working with governments, civil society and the private sector, we are focused on enhancing the quality of life for people as they age. We serve as the global voice for AARP, a social change organization with a membership of more than 37 million.

THE JOURNAL ONLINE

aarpinternational.org/journal

AARP INTERNATIONAL ONLINE

aarpinternational.org

FACEBOOK

facebook.com/aarpintl

TWITTER

@aarpintl

CONTACT

AARP International

601 E Street, NW

Washington, DC 20049

United States

T +1 2024342398

E international@aarp.org

AARP International: The Journal is a publication of AARP. The views expressed herein do not necessarily represent policies of AARP and should not be construed as endorsements. The mention of a product or service herein is solely for information to our readers and may not be used for any commercial purpose. AARP, which was established in 1958, is a nonprofit, nonpartisan organization with tens of millions of members ages 50 and older. State offices are located in all 50 states, the District of Columbia, Puerto Rico, and the Virgin Islands.

January 2018

()2018, AARP

Reprinting with permission only. 